\title{
Epithelial Membrane Antigen, Vimentin, Desmin, Calretinin, E-Cadherin on Cell Block Preparations to Distinguish Well Differentiated Adenocarcinoma from Benign, Reactive, Atypical Mesothelial Cells
}

\author{
Neha Jaiswal ${ }^{1}$, Jayant Makrande², Sunita Vagha ${ }^{3}$ \\ 1, 2, 3 Department of Pathology, Jawaharlal Nehru Medical College, \\ Sawangi, Meghe, Wardha, Maharashtra, India.
}

\section{ABSTRACT}

\section{BACKGROUND}

Inconclusive cytomorphology often results due to failure to distinguish between adenocarcinoma cells from benign, reactive, atypical mesothelial cells in effusion specimens. To resolve such dilemmas, auxiliary techniques like immunohistochemistry were utilised to reach a definitive diagnosis for better treatment and management of patients. We wanted to compare cytodiagnosis achieved on cell block preparations with the cytodiagnosis on conventional smear and perform immunohistochemistry for epithelial membrane antigen (EMA), calretinin, desmin, vimentin and E-cadherin on cell block preparation of the fluids in cases of indistinguishable cytomorphology of adenocarcinoma and reactive, atypical, and benign mesothelial hyperplasia.

\section{METHODS}

The immunohistochemical markers namely EMA, calretinin, vimentin, desmin and Ecadherin were applied on cell blocks employing streptavidin-biotin method. Immunohistochemistry was interpreted by giving scores to the percentage of stained cells.

\section{RESULTS}

EMA and E-cadherin had $100 \%$ sensitivity in diagnosing adenocarcinoma whereas calretinin, vimentin and desmin were $100 \%$ sensitive in diagnosing reactive, atypical mesothelial carcinoma on the cell block preparations.

\section{CONCLUSIONS}

Immunocytochemistry of fluid should be carried out on the cell block preparation where cytological diagnosis on conventional smear and cell block fails to detect malignant cells in the preparation.

\section{KEY WORDS}

Cell Block, Adenocarcinoma, Mesothelial Cells, Immunohistochemistry, EMA, Calretinin, Vimentin, Desmin, E-Cadherin
Corresponding Author:

Dr. Neha Jaiswal,

Meghe Heights Building 2,

Jawaharlal Nehru Medical College,

Sawangi, Meghe, Wardha,

Maharashtra, India.,

E-mail: nehangpjaiswal@gmail.com

DOI: $10.14260 /$ jemds/2021/275

How to Cite This Article:

Jaiswal N, Makrande J, Vagha S. Epithelial membrane antigen, vimentin, desmin, calretinin, e-cadherin on cell block preparations to distinguish well differentiated adenocarcinoma from benign, reactive, atypical mesothelial cells. J Evolution Med Dent Sci 2021;10(18): 1302-1308, DOI:

10.14260/jemds/2021/275

Submission 17-11-2020,

Peer Review 24-02-2021,

Acceptance 01-03-2021,

Published 03-05-2021.

Copyright (C) 2021 Neha Jaiswal et al. This is an open access article distributed under Creative Commons Attribution License [Attribution 4.0 International (CC BY 4.0)] 


\section{BACKGROUND}

Exfoliative cytology remained a mainstay diagnostic tool in evaluation of fluids in the potential spaces located at pleura, peritoneum and pericardium. The biochemical analysis of these fluids provides the information but not to the extent to arrive at a certain diagnosis which could only be achieved until the fluid is submitted for microscopy.1,2,3,4,5 The conventional cytological method is used to examine the fluid for its sediment smear preparations. Conventional cytology preparations have drawbacks of non-sampling of cells, multiple preparations, cellular artefacts or preservations and most importantly the situations of indistinguishable cytomorphology. The sensitivity and specificity of conventional cytology as literature was quoted to have a long range of $80 \%-94 \%$ and $85 \%$ - $95 \%$ respectively. ${ }^{6,7,8}$ Therefore, attempts were made to, concentrate on the cell for its yield and preservation of morphology by upgraded techniques such as liquid based cytology. However, the life-like arrangement of the cells, avoidance of artefact and problems of indistinguishable cytomorphology still remains. ${ }^{9,10,11,12}$

Cell block preparations of the fluid which runs distinct for its advantages of diagnostic evaluation remains as one of the alternative for its better figures of diagnostic accuracy reaching of up to $97 \%$ and typing of various neoplastic and non-neoplastic lesions in the submitted sample of fluid originating at various sites. ${ }^{13,14,15,16}$ However the cell blocks on occasions found to be unrewarding at a few diagnostic dilemma that exist with conventional cytology, liquid based cytology and cell block studies to distinguish between the overlap cytomorphology of reactive atypical mesothelial cells and cells of low-grade adenocarcinoma infiltrate in pleural, peritoneal, pericardial and other fluids. 17,18,19,20

The cell block with its several advantages offers a distinct advantage that its section can be submitted for immunohistochemistry. The immunohistochemistry on the cell block often helps to resolve the dilemma of interpretation of overlap cytomorphology. Cell block have therefore been popular diagnostic tool as it limits the microscopic field, high cell yield, maintains closeness of cellular structure much similar to histomorphology and are suitable for molecular studies. ${ }^{21}, 22,23,24$ It is difficult and inconclusive to separate benign atypical mesothelial cells from cells of low-grade adenocarcinoma on light microscopy in sections of cell block. 25,26,27,28,29 Immunohistochemistry for EMA, calretinin, vimentin, desmin, E-cadherin on sections of cell block identifies epithelial cells while immunohistochemistry of calretinin, vimentin and desmin identified reactive mesothelial cells. The practicing pathologist often face this dilemma of interpretation of misdiagnosing mesothelial cells as adenocarcinoma cells and vice-versa which has affected the tumour evaluation for its staging and treatment. ${ }^{30}$ Detecting malignant cells by immunohistochemical means has increased the diagnostic sensitivity and specificity of cell block studies to a greater extent.

Epithelial membrane antigen and E-cadherin are molecular markers that are known to exist in the cells of epithelium while vimentin, desmin and calretinin are known to exist in the mesothelial cells irrespective of the morphological type. This molecular expression of EMA and Ecadherin for epithelial cells and of vimentin, desmin and calretinin for mesothelial cells therefore provides definite diagnostic support when it is demonstrated by immunohistochemical and immunocytochemical primary monoclonal antibodies. ${ }^{31,22,23,24,32}$ The present study has been planned to explore the immunohistochemistry characterization of epithelial cells, reactive atypical mesothelial cells and distinction between the two if their morphologies are not concluded distinctly on conventional smear and cell block preparation.

\section{Objectives}

- To evaluate immunohistochemical identification of malignant glandular epithelial cells and benign reactive atypical mesothelial cells on sections of cell block prepared from effusions originating at various places.

- To compare cytodiagnosis achieved on cell block preparation with the cytodiagnosis on conventional smear.

- To perform immunohistochemistry for EMA, calretinin, desmin, vimentin and E-cadherin on cell block preparation of the fluids in cases of indistinguishable cytomorphology of adenocarcinoma and reactive, atypical, benign mesothelial hyperplasia.

\section{METHODS}

The present study was carried out in the Department of Pathology in the division of Cytopathology, Jawaharlal Nehru Medical College, Sawangi, Wardha for a period of 2 years ( $1^{\text {st }}$ of August 2018 - 31 st of July 2020) with the following material and methods. A total of seventy-five cases of effusions underwent conventional smear examination, cell block study and immunohistochemistry by a panel of five antibodies consisting of EMA, vimentin, desmin, calretinin and Ecadherin.

Sample size determined by using Krejcie and Morgan Methodology.33for evaluating the justified sample size. Following equation was utilized.

$$
S=\frac{\mathrm{X}^{2} \cdot \mathrm{N} \cdot \mathrm{P}(1-\mathrm{P})}{\mathrm{d}^{2}(\mathrm{~N}-1)+\left[\mathrm{X}^{2} \mathrm{P}(1-\mathrm{P})\right]}
$$

Where -

S - Justified sample size to be evaluate

Statistical analysis: $\mathrm{X}^{2}$ - Chi square value for 1 degree of freedom at some desired probability, this is 3.84 at $5 \%$ level of significance.

$\mathrm{N}$ - Average number of patients diagnosed with adenocarcinoma and benign atypical mesothelial reaction on fluids.

$\mathrm{P}-50 \%$ (0.5) proportion, ' $\mathrm{q}$ ' = 1-P = 50 \% (where $\mathrm{P}$ is Known event and $\mathrm{q}$ is taken as unknown event)

$\mathrm{d}$ - Degree of accuracy (5\%), expressed as a proportion (.05), it is margin of error.

Study subjects were divided into 3 groups of twenty-five patients each.

- Group A - Twenty-five samples of cyto-diagnosed as Adenocarcinoma on conventional cytology and confirmed on cell block from various body fluids. 
- Group B - Twenty-five samples of cyto-diagnosed as Reactive mesothelial cell hyperplasia and confirmed on cell block from various body fluids. Group A and B were utilized as controls for the comparisons of the results of Immunohistochemistry with study Group C.

- Group C - Twenty-five cases of indistinguishable cytomorphology or overlap cytomorphology that failed to make definite diagnosis either of adenocarcinoma or of atypical reactive mesothelial cell hyperplasia on preparation of conventional cytology.

\section{Conventional Smear Preparation $9,34,35,36$}

Fresh fluid samples of effusion were taken in $50 \mathrm{ml}$ test tubes and centrifuged for 15 minutes at $1500 \mathrm{rpm}$. The supernatant was discarded, and the sediment obtained was used to prepare smear. A total of six smears were made from each sample. Three of the smears were wet fixed with $95 \%$ ethyl alcohol and were stained by Papanicolaou stain. Dry smears were stained by standard steps of May-Grunwald Giemsa.

\section{Cell Block Technique $\mathbf{1 6 , 3 7 , 3 8 , 2 1}$}

Fluid samples were centrifuged at $3000 \mathrm{rpm}$ for 5 minutes. The supernatant was discarded. Then, 2 - 3 drops of pooled plasma were mixed with the sediment followed by addition of 4 drops of thromboplastin and was mixed again. Then, the tube was kept undisturbed for five minutes for formation of cell button. For fixation the clot was transferred to a filter paper premoistened with formalin fixative. The filter paper with the sediment was wrapped and placed in tissue cassettes. The cassettes were processed by conventional histopathological technique. Cell blocks obtained were sectioned at 5 micrometre thickness and was stained by haematoxylin and eosin stain.

\section{Immunohistochemistry Technique $39,28,30,40$}

Immunohistochemistry was performed on two sections of 4 5 micron thick from each block. Heat induced antigen retrieval was performed with the help of a pressure cooker. $3 \%$ hydrogen peroxide was applied for 10 minutes for peroxidase blocking. The primary antibody was applied to the slides and was allowed to react for 30 minutes at room temperature followed by a wash with phosphate buffer saline. Then, the secondary antibody (streptavidin-biotin) was applied and allowed to react for 30 minutes at room temperature and then was washed with Peripheral blood smear (PBS). The slides were treated with 3, 3-diaminobenzidine for 15 minutes for colour development. Sections were washed, counterstained with haematoxylin and dehydrated. Xylene was used for clearing the slides. The slides were mounted with DPX.

\begin{tabular}{|cc|}
\hline Score & Percentages of Stained Cells \\
0 & $0 \%$ \\
$1+$ & $<10 \%$ \\
$2+$ & $10-50 \%$ \\
$3+$ & $>50 \%$ \\
\hline Table 1. Immunohistochemistry Scoring for All Study Tissue Markers \\
\hline
\end{tabular}

The steps were similar for EMA, calretinin, vimentin, desmin and E-cadherin. Immunohistochemistry was interpreted by giving scores to the percentage of stained cells. ${ }^{30,} 41$

\section{Statistical Analysis}

$\mathrm{X} 2$ - Chi square value for 1 degree of freedom at some desired probability, this is 3.84 at $5 \%$ level of significance.

$\mathrm{N}$ - Average number of patients diagnosed with adenocarcinoma and benign atypical mesothelial reaction on fluids.

$\mathrm{P}-50 \%$ (0.5) proportion, ' $\mathrm{q}$ ' = 1-P = $50 \%$ (where $\mathrm{P}$ is Known event and $q$ is taken as unknown event)

$\mathrm{d}$ - Degree of accuracy (5\%), expressed as a proportion (.05), it is margin of error.

\section{RESULTS}

All these cases of group A, B and C were studied by cell block. The comparison between conventional cytology with that of cell block diagnosis is shown in Table 4 .

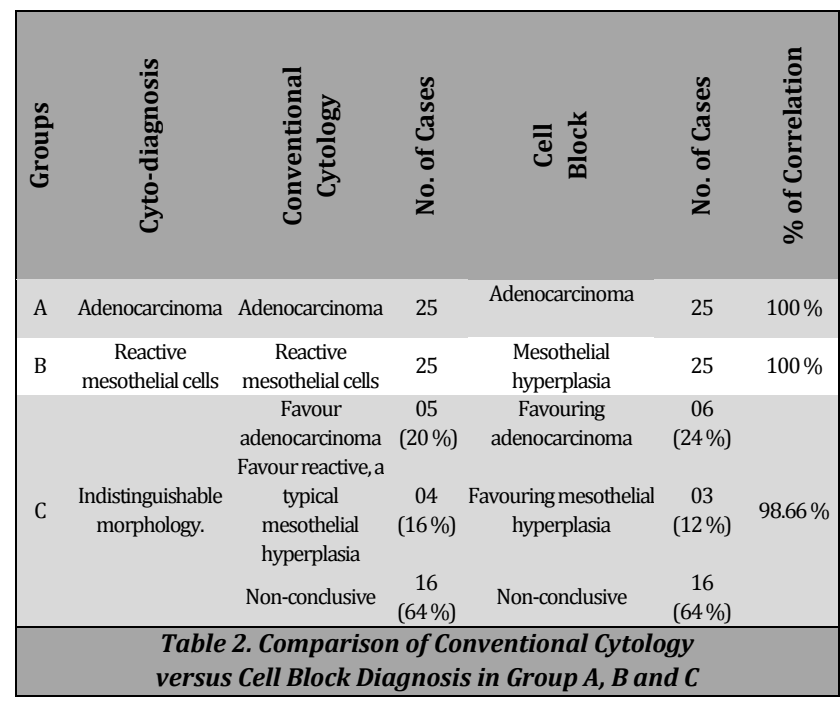

The cell block study could additionally bring out the cytodiagnosis of adenocarcinoma in a single case. Conventional cytology of this case was indistinguishable but stratified as favour atypical, reactive mesothelial cells hyperplasia. 16 diagnosis which were inconclusive in Group C of indistinguishable cytomorphology remained still inconclusive on cell block study. The correlation for accuracy of group A is $100 \%$, group B is $100 \%$ \& for group C is 98.66 $\%$.

\section{Immunocytochemistry}

The control group A showed a well-demarcated pattern of immunoreactivity for the cells of adenocarcinoma. In group A of adenocarcinoma EMA and E-cadherin were positive with grade 2 and grade 3 scores while the other marker of calretinin, vimentin and desmin showed mostly the negative results for adenocarcinoma cells. Group of atypical, reactive mesothelial cells showed positivity for calretinin, vimentin and desmin with $2+$ and $3+$ score in all 25 cases and showed negative results for EMA and E-cadherin. The group C of indistinguishable cytomorphology upon the immunohistochemical evaluation of EMA, calretinin, vimentin, desmin, E-cadherin on cell block sections have shown the reassignment of diagnosis in 5 cases. 


\begin{tabular}{|c|c|c|c|c|c|c|c|c|c|c|c|c|c|c|c|c|c|c|c|c|}
\hline \multicolumn{21}{|c|}{ Group A (Adenocarcinoma) } \\
\hline No of Cases & \multicolumn{4}{|c|}{ EMA } & \multicolumn{4}{|c|}{ Calretinin } & \multicolumn{4}{|c|}{ Vimentin } & \multicolumn{4}{|c|}{ Desmin } & \multicolumn{4}{|c|}{ E-Cadherin } \\
\hline \multirow{2}{*}{25} & 0 & 1 & 2 & 3 & 0 & 1 & 2 & 3 & 0 & 1 & 2 & 3 & 0 & 1 & 2 & 3 & 0 & 1 & 2 & 3 \\
\hline & 00 & 00 & 10 & 15 & 24 & 01 & 00 & 00 & 24 & 01 & 00 & 00 & 23 & 02 & 00 & 00 & 00 & 01 & 12 & 12 \\
\hline \multicolumn{21}{|c|}{$X^{2}=99.07, P$-value -0.0001 (significant) } \\
\hline \multicolumn{21}{|c|}{ Group B (reactive mesothelial cell hyperplasia) } \\
\hline \multicolumn{5}{|c|}{ EMA } & \multicolumn{4}{|c|}{ Calretinin } & \multicolumn{4}{|c|}{ Vimentin } & \multicolumn{4}{|c|}{ Desmin } & \multicolumn{4}{|c|}{ E-Cadherin } \\
\hline \multirow{2}{*}{25} & 0 & 1 & 2 & 3 & 0 & 1 & 2 & 3 & 0 & 1 & 2 & 3 & 0 & 1 & 2 & 3 & 0 & 1 & 2 & 3 \\
\hline & 24 & 01 & 00 & 00 & 00 & 00 & 05 & 20 & 00 & 01 & 05 & 19 & 00 & 01 & 10 & 14 & 23 & 02 & 00 & 00 \\
\hline \multicolumn{21}{|c|}{ Table 3. Immunohistochemistry in Group A and $B(N=25)$} \\
\hline
\end{tabular}

\begin{tabular}{|c|c|c|c|c|c|c|c|c|c|c|c|c|c|c|c|c|c|c|c|c|c|c|}
\hline \multicolumn{22}{|c|}{ Group C (Indistinguishable Cytomorphology) } & \multirow{3}{*}{$\begin{array}{l}\text { After IHC } \\
\text { Diagnosis }\end{array}$} \\
\hline \multirow{2}{*}{ Diagnosis } & \multirow{2}{*}{$\begin{array}{l}\text { Number } \\
\text { of Cases }\end{array}$} & \multicolumn{4}{|c|}{ EMA } & \multicolumn{4}{|c|}{ E-Cadherin } & \multicolumn{4}{|c|}{ Vimentin } & \multicolumn{4}{|c|}{ Desmin } & \multicolumn{4}{|c|}{ Calretinin } & \\
\hline & & $\mathbf{0}$ & 1 & 2 & 3 & $\mathbf{0}$ & 1 & 2 & 3 & $\mathbf{0}$ & 1 & 2 & 3 & $\mathbf{0}$ & 1 & 2 & 3 & $\mathbf{0}$ & 1 & 2 & 3 & \\
\hline $\begin{array}{c}\text { Favour } \\
\text { adenocarcinoma }\end{array}$ & 06 & 00 & 00 & 05 & 06 & 00 & 00 & 02 & 09 & 09 & 02 & 00 & 00 & 07 & 04 & 00 & 00 & 10 & 01 & 00 & 00 & $6+5=11$ \\
\hline $\begin{array}{c}\text { Favour reactive } \\
\text { mesothelial hyperplasia }\end{array}$ & 03 & 02 & 00 & 00 & 00 & 02 & 00 & 00 & 02 & 00 & 00 & 01 & 01 & 00 & 00 & 01 & 01 & 00 & 00 & 00 & 02 & $3-1=2$ \\
\hline Inconclusive & 16 & 12 & 00 & 01 & 03 & 12 & 00 & 02 & 02 & 04 & 00 & 05 & 07 & 02 & 02 & 05 & 07 & 04 & 00 & 02 & 10 & $16-4=12$ \\
\hline \multicolumn{23}{|c|}{ Table 4. Immunocytochemistry in Group C $(N=25)$} \\
\hline
\end{tabular}

\begin{tabular}{|c|c|c|c|c|c|c|c|}
\hline Markers & Sensitivity & Specificity & $\begin{array}{c}\text { Positive Predictive } \\
\text { Value }\end{array}$ & $\begin{array}{c}\text { Negative } \\
\text { Predictive Value }\end{array}$ & $\begin{array}{l}\text { Likelihood } \\
\text { Ratio }\end{array}$ & Diagnostic Accuracy & P -Value \\
\hline EMA & $100 \%$ & $73.68 \%$ & $54.55 \%$ & $100 \%$ & 3.8 & $80 \%$ & 0.001 \\
\hline E-cadherin & $100 \%$ & $73.68 \%$ & $54.55 \%$ & $100 \%$ & 3.8 & $80 \%$ & 0.001 \\
\hline Vimentin & $100 \%$ & $54.55 \%$ & $73.68 \%$ & $100 \%$ & 2.20 & $80 \%$ & 0.001 \\
\hline Desmin & $100 \%$ & $54.55 \%$ & $73.68 \%$ & $100 \%$ & 2.20 & $80 \%$ & 0.001 \\
\hline Calretinin & $100 \%$ & $54.55 \%$ & $73.68 \%$ & $100 \%$ & 2.20 & $80 \%$ & 0.001 \\
\hline \multicolumn{8}{|c|}{ Table 5. Statistics of Individual Molecular Marker Assessment (Group C) } \\
\hline
\end{tabular}

\section{DISCUSSION}

The present study has observed $100 \%$ correlation in group A and $\mathrm{B}$ between the cytodiagnosis on conventional smear cytology and cell block studies that is group A of adenocarcinoma and group $\mathrm{B}$ of reactive mesothelial cells respectively. Such a confirmation on comparison for accuracy of conventional cytology and cell block studies have been reported in the studies of Murugan et al. Bista P et al. Nathan et al. ${ }^{15}$ Amiri et al. ${ }^{14}$

However, in the studies of Shivkumarswamy et al. ${ }^{35}$ Shukla et al. ${ }^{38}$ Bansode et al. ${ }^{16}$ Katti et al. ${ }^{6}$ Sharma et al. ${ }^{42}$ Aggarwal et al. ${ }^{43}$ and Nautiyal et al. ${ }^{41}$ showed that cell block performed more efficiently than conventional cytology. The present study for Group $\mathrm{C}$ that is of indistinguishable cytomorphology when carried out and compared between the conventional cytology and cell block studies has observed that a case has changed its category to adenocarcinoma Group yielding the percent of correlation of $98.66 \%$.

The present study has appreciated the advantage of cell block in its utility for immunohistochemistry as it offers not only histology like sections, but it also limits the area of microscopy similarly for this advantage of cell block with many other studies. ${ }^{43,16,6,41}$

\section{Epithelial Membrane Antigen}

The sensitivity of EMA at detecting adenocarcinoma cells as reviewed in the present work is $100 \%$ which is similar to the sensitivity quoted in the studies of Singh et al.24 (100\%), Murugan et al. (100\%), Hasteh et al.44 (100\%) and Aggarwal et al. $(100 \%) .{ }^{43}$

The present study has reported specificity of $73.68 \%$ for EMA at diagnosis of adenocarcinoma on the cell block study which is not in agreement with the studies of Murugan et al
(97.37 \%), Aggarwal et al. (93.75\%), Nautiyal et al. ${ }^{41}$ (100\%), Subbararyan et al. ${ }^{45}(92.86 \%)$ for high rate of specificity approaching to $100 \%$. The present study has observed PPV of $54.55 \%$ and NPV of $100 \%$. which does not correspond to the PPV values but corresponds to the NPV values in the results of Murugan et al. (PPV 97.5 \%, NPV $100 \%$ ) and Aggarwal et al. ${ }^{43}$ (PPV $90 \%$ NPV $100 \%$ ). The present study has likelihood ratio of 3.80 and P-value of 0.001 which is significant and is similar to that of results of Hasteh et al. ${ }^{44}$ (0.001).

\section{E-Cadherin}

The present study has observed sensitivity of $100 \%$ for Ecadherin at detection of adenocarcinoma cells which is similar with the sensitivity quoted in the studies of Hirome et al. ${ }^{46}$ (87 $\%$ ), Murugan et al. (97\%) and Moghaddam et al. ${ }^{47}$ (88 \%). The specificity of $73.68 \%$ was observed for E-cadherin at detection of adenocarcinoma which is lesser than the specificity quoted by Xue ying su et al. ${ }^{27}(100 \%)$ and Moghaddam et al.47 (92\%) but higher than the specificity quoted by Murugan et al (68.42\%). The present study observed PPV of $54.55 \%$ and NPV of $100 \%$ which does not correspond to the PPV and NPV value in the results of Murugan et al (PPV $76 \%$, NPV $96.3 \%$ ) and Moghaddam et al. ${ }^{47}$ (PPV $91.6 \%$, NPV $88.4 \%$ ).

The likelihood ratio and P-value for E-cadherin in the diagnosis of adenocarcinoma reported in the present study was 3.80 and 0.001 , respectively which is significant and is similar to that of the results of Murugan et al. (LR-3.085, Pvalue $<0.0001$ ).

\section{Calretinin}

The present study has observed the sensitivity of $100 \%$ which is similar to the sensitivity quoted in the studies of Murugan et 
al. (100\%), Hirome et al. ${ }^{46}$ (100\%), Subbarayan et al. ${ }^{45}$ (100 $\%)$, Aggarwal et al. (100\%).

The present study reported a specificity of $54.55 \%$ for calretinin in diagnosis of reactive mesothelial cells which is not in agreement with the studies of Nautiyal et al. ${ }^{41}(100 \%)$ Subbarayan et al.45 (97.62 \%), Heon kim et al. ${ }^{29}$ (98\%), Aggarwal et al (94.4\%), Murugan et al. (92.31\%).

The present study has observed the PPV of $73.68 \%$ which does not correspond to the values recorded in the studies of Murugan et al (92.68 \%), and Subbarayan et al. (97.67\%) while the NPV of $100 \%$ recorded in the present study is in concordance with the studies of Aggarwal et al, Murugan et al and Subbarayan et al.

The likelihood ratio for calretinin in diagnosis of reactive mesothelial cells reported in the present study was 2.20 and Pvalue of 0.001 which is significant and similar to the results of Murugan et al. (LR-13.000, P value < 0.0001).

\section{Vimentin}

The present study observed sensitivity of $100 \%$ which is similar to the study of Keith et al. ${ }^{31}(100 \%)$ but dissimilar to the sensitivity quoted in the study of Murugan et al. (74\%). The present study observed specificity of $54.55 \%$ which is lesser than the one reported by Murugan et al. (74.9\%). The PPV of vimentin for recognition of reactive mesothelial cells recorded in the present study was $73.68 \%$ which corresponds to the values recorded in the study of Murugan et al. (77.78\%) and NPV of $100 \%$ which did not correspond to the values recorded in the study of Murugan et al. (NPV $75.61 \%$ ). The present study has likelihood ratio of 2.20 and $P$ value of 0.001 which is significant and is similar to that of the results of Murugan et al. (LR 3.592, P-value < 0.0001).

\section{Desmin}

Murugan et al. in their evaluation of desmin as a marker for reactive mesothelial cells has observed the sensitivity of $55 \%$, specificity of $95.12 \%$, positive predictive value of $91.3 \%$, negative predictive value of $69.64 \%$, likelihood ratio of 11.329 and P-value of 0.0001 . The present study observed sensitivity of $100 \%$, specificity of $54.55 \%$, positive predictive value of $73.68 \%$, and negative predictive value of $100 \%$ and P-value of 0.001 .

The sensitivity reported in the present study is $100 \%$ which is higher than what is reported by Murugan et al. ${ }^{30}$ (55 $\%$ ) and Hasteh et al. $^{44}$ (84 \%) and is similar to Gill et al. ${ }^{25}$ (100 $\%$ ). The study of Gill et al. ${ }^{25}$ and Hasteh et al. also reported the $\mathrm{P}$ value for its diagnostic capacity and showed it to be significant, $<0.0001$ and 0.001 respectively. The present study also observed high P-value of 0.001 for the detection of reactive mesothelial cells which is similar to that of the results of Hasteh et al. 44

If the five molecular markers were used in combination for the 25 cases of study group (C) have shown the sensitivity of $54.55 \%$, specificity of $100 \%$, positive predictive value of 100 $\%$, negative predictive value of $73.68 \%$ and diagnostic accuracy of $80 \%$ as depicted in Table 7 .

The individual marker and their sensitivity, specificity, positive predictive value, negative predictive value, positive likelihood ratio and negative likelihood ratio is shown in Table 8.

EMA and E-cadherin was found to have the highest sensitivity of $100 \%$ for adenocarcinoma cells and specificity of $73.68 \%$ with the similar positive predictive value $(54.55$ $\%)$, negative predictive value $(100 \%)$ and likelihood ratio of 3.8 .

Vimentin, desmin, calretinin for their capacity to identify the mesothelial cells was found to have sensitivity of $100 \%$ and specificity of $54.55 \%$ individually. The positive predictive value and negative predictive value of all these three markers were $73.68 \%$ and $100 \%$ for mesothelial cells, respectively. The likelihood ratio for vimentin, desmin, calretinin individually was 2.20 .

\section{CONCLUSIONS}

Cell block studies offer the advantages of limited areas of microscopy and lifelike cytoarchitectural features similar to histology and are suitable for immunohistochemical examination. Immunocytochemistry on the cell block preparation of the fluids of pleural, peritoneal, and pericardial type is of immense diagnostic value if epithelial (EMA and Ecadherin) and mesothelial markers (calretinin, vimentin and desmin) are combined in a panel. Such application resolves the diagnostic dilemma in the cytomorphology which are otherwise indistinguishable and show overlap.

Data sharing statement provided by the authors is available with the full text of this article at jemds.com.

Financial or other competing interests: None.

Disclosure forms provided by the authors are available with the full text of this article at jemds.com.

\section{REFERENCES}

[1] Hajdu SI, Ehya H. A note from history: foundation of diagnostic cytology. Ann Clin Lab Sci 2008;38(3):296-9.

[2] Tabatabai ZL, Nayar R, Souers RJ, et al. Performance characteristics of body fluid cytology analysis of 344380 responses from the college of American pathologists interlaboratory comparison program in nongynecologic cytopathology. Arch Pathol Lab Med 2018;142(1):53-8.

[3] Tetikkurt C, Yılmaz N, Tetikkurt S, et al. The value of exfoliative cell cytology in the diagnosis of exudative pleural effusions. Monaldi Arch Chest Dis 2018;88(3):944.

[4] Kopcinovic LM, Culej J. Pleural, peritoneal and pericardial effusions-a biochemical approach. Biochem Med (Zagreb) 2014;24(1):123-37.

[5] Dowerah E, Das S. Cytological evaluation of peritoneal fluid with special reference to malignancy. Int J Bio Res 2014;5(6):396-8.

[6] Katti R, Bommanahalli BP, Murthy N. Diagnostic role of cell block method in serous effusions: a comparative study with conventional smear cytology. Ind Jour of Pathol and Oncol 2016;3(2):281-4.

[7] Schofield K, D'Aquila T, Rimm DL. The cell adhesion molecule, e-cadherin, distinguishes mesothelial cells from carcinoma cells in fluids. Cancer 1997;81(5):293-8. 
[8] Babloyan S, Voulgaris Z, Papaefthimiou M, et al. Comparison of quality between conventional and thinprep cytology in investigation of patients with epithelial ovarian cancer. The New Armenian Medical Journal 2009;3(3):22-8.

[9] Alwahaibi NY, Alnoumani NS, Bai UR. Comparison of ThinPrep ${ }^{\circledR}$ and conventional preparations for peritoneal and pleural cytology smear. A Nnual Research And Review in Biology 2014;4(20):3139-49.

[10] Pawar PS, Gadkari RU, Swami SY, et al. Comparative study of manual liquid-based cytology (MLBC) technique and direct smear technique (conventional) on fine-needle cytology/fine-needle aspiration cytology samples. J Cytol 2014;31(2):83-6.

[11] Morimoto A, Ito A, Hashimoto K, et al. New diagnostic technique for rapid fluorescence immunocytochemical staining of adenocarcinoma and mesothelial cells using liquid-based cytology. Acta Cytol 2014;58(5):461-8.

[12] Hafez NH, Shaaban HM. Sure path liquid-based cytology versus conventional smears for interpretation of serous effusion fluids: a study of 104 cases. Egyptian Journal of Pathology 2018;38(1):154-61.

[13] Sakamoto H, Takenaka M, Ushimaru K, et al. Use of liquidbased cytology (LBC) and cell blocks from cell remnants for cytologic, immunohistochemical and immunocytochemical diagnosis of malignancy. Open Journal of Pathology 2012;2(3):58-65.

[14] Amiri Z, Momtahan M, Mokhtari M. Comparison of conventional cytology, liquid-based cytology and cell block in the evaluation of peritoneal fluid in gynecology malignancies. Acta Cytol 2019;63(1):63-72.

[15] Nathan NA, Narayan E, Smith MM, et al. Cell block cytology: improved preparation and its efficacy in diagnostic cytology. Am J Clin Pathol 2000;114(4):599606.

[16] Bansode S, Kumbalkar D, Nayak S. Evaluation of cell block technique in the cytodiagnosis of body fluids. Int J Sci Res 2015;4:87-94

[17] Fetsch PA, Simsir A, Brosky K, et al. Comparison of three commonly used cytologic preparations in effusion immunocytochemistry. Diagn Cytopathol 2002;26(1):616.

[18] Dey S, Nag D, Nandi A, et al. Utility of cell block to detect malignancy in fluid cytology: adjunct or necessity? J Cancer Res Ther 2017;13(3):425-9.

[19] Thapar M, Mishra RK, Sharma A, et al. Critical analysis of cell block versus smear examination in effusions. J Cytol 2009;26(2):60-4.

[20] Khan S, Omar T, Michelow P. Effectiveness of the cell block technique in diagnostic cytopathology. J Cytol 2012;29(3):177-82.

[21] Kulkarni MB, Desai SB, Ajit D, et al. Utility of the thromboplastin-plasma cell-block technique for fineneedle aspiration and serous effusions. Diagn Cytopathol 2009;37(2):86-90.

[22] Shield PW, Callan JJ, Devine PL. Markers for metastatic adenocarcinoma in serous effusion specimens. Diagn Cytopathol 1994;11(3):237-45.

[23] Chen CJ, Chang SC, Tseng HH. Assessment of immunocytochemical and histochemical stainings in the distinction between reactive mesothelial cells and adenocarcinoma cells in body effusions. Zhonghua Yi Xue Za Zhi (Taipei) 1994;54(3):149-55.

[24] Singh HK, Silverman JF, Berns L, et al. Significance of epithelial membrane antigen in the work-up of problematic serous effusions. Diagn Cytopathol 1995;13(1):3-7.

[25] Gill SA, Meier PA, Kendall BS. Use of desmin immunohistochemistry to distinguish between mesothelial cells and carcinoma in serous fluid cell block preparations. Acta Cytol 2000;44(6):976-80.

[26] Ko EC, Jhala NC, Shultz JJ, et al. Use of a panel of markers in the differential diagnosis of adenocarcinoma and reactive mesothelial cells in fluid cytology. Am J Clin Pathol 2001;116(5):709-15.

[27] Su XY, Li GD, Liu HB, et al. Significance of combining detection of E-cadherin, carcinoembryonic antigen and calretinin in cytological differential diagnosis of serous effusion. Ai Zheng 2004;23(10):1185-9.

[28] Ueda J, Iwata $T$, Ono $M$, et al. Comparison of three cytologic preparation methods and immunocytochemistries to distinguish adenocarcinoma cells from reactive mesothelial cells in serous effusion. Diagn Cytopathol 2006;34(1):6-10.

[29] Kim JH, Kim GE, Choi YD, et al. Immunocytochemical panel for distinguishing between adenocarcinoma and reactive mesothelial cells in effusion cell blocks. Diagn Cytopathol 2009;37(4):258-61.

[30] Murugan P, Siddaraju MN, Habeebullah S, et al. Immunohistochemical distinction between mesothelial and adenocarcinoma cells in serous effusions: a combination panel-based approach with a brief review of literature. Indian J Pathol Microbiol 2009;52(2):175-81.

[31] Nance KV, Silverman JF. Immunocytochemical panel for the identification of malignant cells in serous effusions. Am J Clin Pathol 1991;95(6):867-74.

[32] Kuperman M, Florence RR, Pantanowitz L, et al. Distinguishing benign from malignant mesothelial cells in effusions by Glut-1, EMA and desmin expression: an evidence-based approach. Diagn Cytopathol 2013;41(2):131-40.

[33] Krejcie RV, Morgan DW. Determining sample size for research activities. Educational and Psychological Measurement 1970;30(3):607-10.

[34] Bhanvadia VM, Santwani PM, Vachhani JH. Analysis of diagnostic value of cytological smear method versus cell block method in body fluid cytology: study of 150 cases. Ethiop J Health Sci 2014;24(2):125-31.

[35] Shivkumarswamy U, Arakeri SU, Karigowdar MH, et al. Diagnostic utility of the cell block method versus the conventional smear study in pleural fluid cytology. J Cytol 2012;29(1):11-5.

[36] Bista P. Comparison of the diagnostic accuracy of cell block with cytology smear in serous effusions. Journal of Pathology of Nepal 2013;3(6):482-6.

[37] Castro-Villabon D, Avello Y, Ruiz N, et al. Implementation of routine thromboplastin-plasma cell block technique in the evaluation of non-gynaecologic specimens: a methodologic comparison with conventional cytology. Journal of Microscopy and Ultrastructure 2014;2(3):17781.

[38] Shukla P, Kaur S, Gulwani HV. Diagnostic utility of plasma thromboplastin cell block preparation in cytological 
evaluation of serous effusions. International Journal of Biomedical Research 2015;6(11):890-96.

[39] Lee JS, Nam JH, Lee MC, et al. Immunohistochemical panel for distinguishing between carcinoma and reactive mesothelial cells in serious effusions. Acta Cytol 1996;40(4):631-6.

[40] Su XY, Li GD, Liu WP, et al. Cytological differential diagnosis among adenocarcinoma, epithelial mesothelioma and reactive mesothelial cells in serous effusions by immunocytochemistry. Diagn Cytopathol 2011;39(12):900-8.

[41] Nautiyal N, Bhardwaj A, Acharya S. Diagnostic utility of Epithelial Membrane Antigen (EMA) and Calretinin (CAL) in effusion cytology. J Clin Diagnc Res 2017;11(5):E36-9.

[42] Sharma M, Singh K. Diagnostic utility of gelatin cell block over conventional cytological smear. J Evid Based Med Healthc 2017;4(39):2347-51.

[43] Aggarwal V, Kumar P, Singh A. Diagnostic utility of the immunohistochemical markers calretinin (CAL) and Epithelial Membrane Antigen (EMA) in differential diagnosis of Reactive Mesothelial Cells (RMC), malignant mesothelioma and metastatic Adenocarcinoma (AC) in serous effusions. International Journal of Science and Research 2016;5(12):298-301.

[44] Hasteh F, Lin GY, Weidner N. The use of immunohistochemistry to distinguish reactive mesothelial cells from malignant mesothelioma in cytologic effusions. Cancer Cytopathol 2010;118(2):90-6.

[45] Subbarayan D, Bhattacharya J. Use of panel of markers in serous effusion to distinguish reactive mesothelial cells from adenocarcinoma. J Cytol 2019;36(1):28-31.

[46] Kitazume H, Kitamura K, Mukai K, et al. Cytologic differential diagnosis among reactive mesothelial cells, malignant mesothelioma and adenocarcinoma: utility of combined e-cadherin and calretinin immunostaining. Cancer 2000;90(1):55-60.

[47] Moghaddam NA, Tahririan R, Eftekhari M, et al. Diagnostic value of E-cadherin and fibronectin in differentiation between reactive mesothelial and adenocarcinoma cells in serous effusions. Adv Biomed Res 2012;1(1):56. 